\title{
The use of high-resolution melting techniques for mutation screening of diseases caused by trinucleotide repeats expansion, with emphasis on the AR gene
}

Achmad Zulfa Juniarto, ${ }^{1}$ Mahayu Dewi Ariani, ${ }^{1}$ Stefani Harumsari, ${ }^{1}$ Nurin Aisyiyah Listyasari, ${ }^{1}$ Hardian, ${ }^{2}$ Agustini Utari, ${ }^{1,3}$ Sultana Muhammad Hussein Faradz ${ }^{1}$

pISSN: 0853-1773 • elSSN: 2252-8083 https://doi.org/10.13181/mji.v28i2.3008 Med J Indones. 2019;28:116-22

Received: July 21, 2018

Accepted: February 2, 2019

Authors' affiliations:

${ }^{1}$ Center for Biomedical Research (CEBIOR), Faculty of Medicine, Universitas Diponegoro, Semarang, Indonesia, '2Department of Physiology, Faculty of Medicine, Universitas Diponegoro, Semarang, Indonesia, ${ }^{3}$ Department of Pediatrics, Faculty of Medicine, Universitas Diponegoro, Semarang, Indonesia

\section{Corresponding author:}

Sultana Muhammad Hussein Faradz

Center for Biomedical Research (CEBIOR), Faculty of Medicine, Universitas Diponegoro, Jl. Prof. Soedarto SH, Tembalang 50275 Semarang, Central Java, Indonesia

Tel/Fax: +62-24-8454714

E-mail: sultanafaradz@gmail.com/

sultana@fk.undip.ac.id

This online publication has been corrected. The corrected version first appeared on July 3, 2020.

\begin{abstract}
BACKGROUND Trinucleotide repeat expansion (TRE) diseases are genetic diseases caused by an increase in the number of CAG, CGG, and CTG codons. CAG repeat expansion in exon 1 of the androgen receptor $(A R)$ gene is known to be associated with disorders of sex development (DSD) and spinal and bulbar muscular atrophy (SBMA). Because the traditional Southern blot for CAG repeat expansion is laborious and time-consuming, this study was aimed to use high-resolution melting (HRM) analysis to screen the CAG repeat length of the AR gene in Indonesian patients with DSD.
\end{abstract}

METHODS In total, 30 male patients with DSD $(46, \mathrm{XY})$, one male patient with SBMA, and 30 healthy males (control) were included in the study. The CAG repeat length was determined using HRM analysis, and Sanger sequencing was used to confirm the CAG repeat length.

RESULTS For the DSD cases and controls, the melting temperature (Tm) was within the normal range of $89-91.05^{\circ} \mathrm{C}$; however, $\mathrm{Tm}$ was $92.65^{\circ} \mathrm{C}$ for the SBMA case. Sanger sequencing confirmed that DSD cases had 13-27 CAG repeats, and the SBMA case had 54 CAG repeats.

CONCLUSIONS HRM analysis using polymerase chain reaction is a sensitive, effective, and rapid technique for screening CAG repeat expansion in exon 1 of the AR gene. This is the first technique for $A R$ gene screening that may be applicable to other TRE diseases.

KEYWORDS androgen receptor, disorders of sex development, genetic screening, hypospadias
Trinucleotide repeat expansion (TRE) diseases are genetic disorders caused by codon repetitions that exceed the normal size in the coding or noncoding region of the genes. ${ }^{1}$ The codon repeat expansion of polyglutamine (CAG) in the androgen receptor (AR) gene is associated with the the X-linked androgen insensitivity syndrome, and that of non-polyglutamine (e.g., CGG) in the FMR1 gene is associated with Fragile $X$ syndrome. ${ }^{2}$ Androgens are responsible for sexual development in males before birth and during puberty. They function through the $A R$ gene, which has 8 exons and is located on X chromosome at q11-12.
Exon 1 of the $A R$ gene located at the $\mathrm{N}$-terminal domain associated with gene regulation contains a CAG repeat sequence, and trinucleotide repeat expansion is a common mutation that occurs in this region. ${ }^{3}$ Mutations in the AR gene are known to be associated with various clinical presentations, from ambiguous genitalia, hypospadias, and micropenis in newborns to azoospermia or oligozoospermia in adults contributing to $2-3 \%$ of male infertility. ${ }^{4}$ In healthy males, the number of CAG repeats varies between 11 and 31; however, the number of CAG repeats is increased in under-masculinized males. ${ }^{5}$ Furthermore, 
the pathogenic effect of CAG repeat expansion is associated with a neurodegenerative disorder, spinal and bulbar muscular atrophy (SBMA) or Kennedy's disease, and a risk of hypospadias in Caucasians. ${ }^{6,7}$

Rapid and simple techniques for mutation screening must be developed, particularly for population studies examining hypospadias and infertility of unknown etiology. Traditionally, gene mutations were detected using Southern blot analysis, which is more laborious, time-consuming, and requires large quantities of DNA.

High resolution melting (HRM) analysis is a simple method for mutation screening of codon repeats and is performed with double-stranded DNA using real-time polymerase chain reaction $(P C R)$ without requiring a post-PCR procedure. ${ }^{8} \mathrm{~A}$ fluorescence dye binds specifically to the DNA as a marker, and melting curves are directly produced by monitoring the fluorescence level. ${ }^{9}$ The HRM machine plots the data as a graph of the fluorescence level against the temperature known as the melting curve. The melting curve for each sample enables the identification of an aberrant graph to detect codon repeat expansion. ${ }^{10}$ This study was aimed to develop a rapid and simple technique to screen CAG repeat expansion in the $A R$ gene using HRM analysis, which can be applied for screening other TRE diseases.

\section{METHODS}

\section{Patients}

This study included 30 male patients with 46 , $X Y$ disorders of sex development (DSD) with clinical phenotypes such as external genitalia abnormality, severe hypospadias, and under-masculinized ambiguous genitalia (Table 1). The control group consisted of 30 healthy males with proven fertility. In addition, one case with clinically diagnosed SBMA was included because SBMA and DSD share the AR mutation. The patient with SBMA showed weakness in the lower limbs, tremor in both hands, and gynecomastia. Chromosome analysis revealed a karyotype of $46, X Y$ in all the patients with DSD and SBMA. The genetic analysis was performed at the Center for Biomedical Research, Faculty of Medicine, Universitas Diponegoro. Ethical approval for this study was obtained from the Institute Research Board, Faculty of Medicine, Universitas Diponegoro and Kariadi Hospital Semarang No. 627/
Table 1. Characteristics of DSD patients

\begin{tabular}{lc}
\hline Characteristics & Result, $n(\%)(n=30)$ \\
\hline Age, mean (SD) & 3 mo-23 y, 6.69 (6.34) \\
\hline Position of urethral opening & $1(3.33)$ \\
\hline Glanular & $2(6.67)$ \\
\hline Coronal & $4(13.33)$ \\
\hline Distal penile & $1(3.33)$ \\
\hline Proximal penile & $2(6.67)$ \\
\hline Phenoscrotal & $13(43.33)$ \\
\hline Scrotal & $7(23.33)$ \\
\hline Perineal & \\
\hline Other genital anomalies & $8 / 30(26.67)$ \\
\hline Micropenis & $8 / 30(26.67)$ \\
\hline Scrotal bifid & \\
\hline Impalpable testes & $2 / 30(6.67)$ \\
\hline Bilateral & $2 / 30(6.67)$ \\
\hline Unilateral
\end{tabular}

DSD=disorders of sex development; SD=standard deviation

EC/FK-RSDK/2016. All patients (or parent or guardian) provided written informed consent prior to their participation in this study.

\section{CAG repeat length analysis}

Blood samples were collected in ethylenediaminetetraacetic acid-containing tubes and were used for molecular genetic analysis. Genomic DNA was extracted using the saltingout method as described elsewhere." The CAG repeat sequence of exon 1 of the $A R$ gene was amplified using the following primers: forward 5'-AGGCACCCAGAGGCCGCGAG-3' and reverse 5'-TAGCCTGTGGGGCCTCTACGAT-3'.12 The PCR reaction mixture comprised $4 \mu$ of the DNA template, $10 \mu \mathrm{l}$ of Type-it ${ }^{\circledR}$ HRM PCR Kit (Qiagen, Hilden, Germany), $2 \mu$ l of forward and reverse primers $(5 \mathrm{pmol} / \mu \mathrm{l})$, and $4 \mu \mathrm{l}$ of purified water to a final volume of $20 \mu \mathrm{l}$. PCR amplification was performed using quantitative PCR (qPCR)-HRM Rotor GeneQ 5Plex HRM 72-well rotor (California, USA) resulting in a 203-bp product. The PCR procedure was as follows: $95^{\circ} \mathrm{C}$ initial denaturation for $10 \mathrm{~min} ; 40 \mathrm{cycles}$ of $94^{\circ} \mathrm{C}$ denaturation for $30 \mathrm{sec}$, $71^{\circ} \mathrm{C}$ annealing for $45 \mathrm{sec}$, and $72^{\circ} \mathrm{C}$ extension for 45 sec; and $80-95^{\circ} \mathrm{C}$ HRM with a temperature increase of $0.1^{\circ} \mathrm{C}$ with each step. Melting curve analysis (MCA) from the post-HRM step was analyzed to estimate the CAC repeat length. Confirmation of the 
CAG repeat length was performed using Sanger sequencing. The statistical significance of the median was analyzed using the Mann-Whitney U-test. Spearman's rank-order correlation was used to determine the association between the CAG repeat length and HRM melting temperature (Tm).

\section{RESULTS}

The CAG repeat length in exon 1 of the $A R$ gene varied from 13 to 27 repeats in all patient samples. The highest repeat frequency of 22 versus 23 repeats was observed in the DSD and control

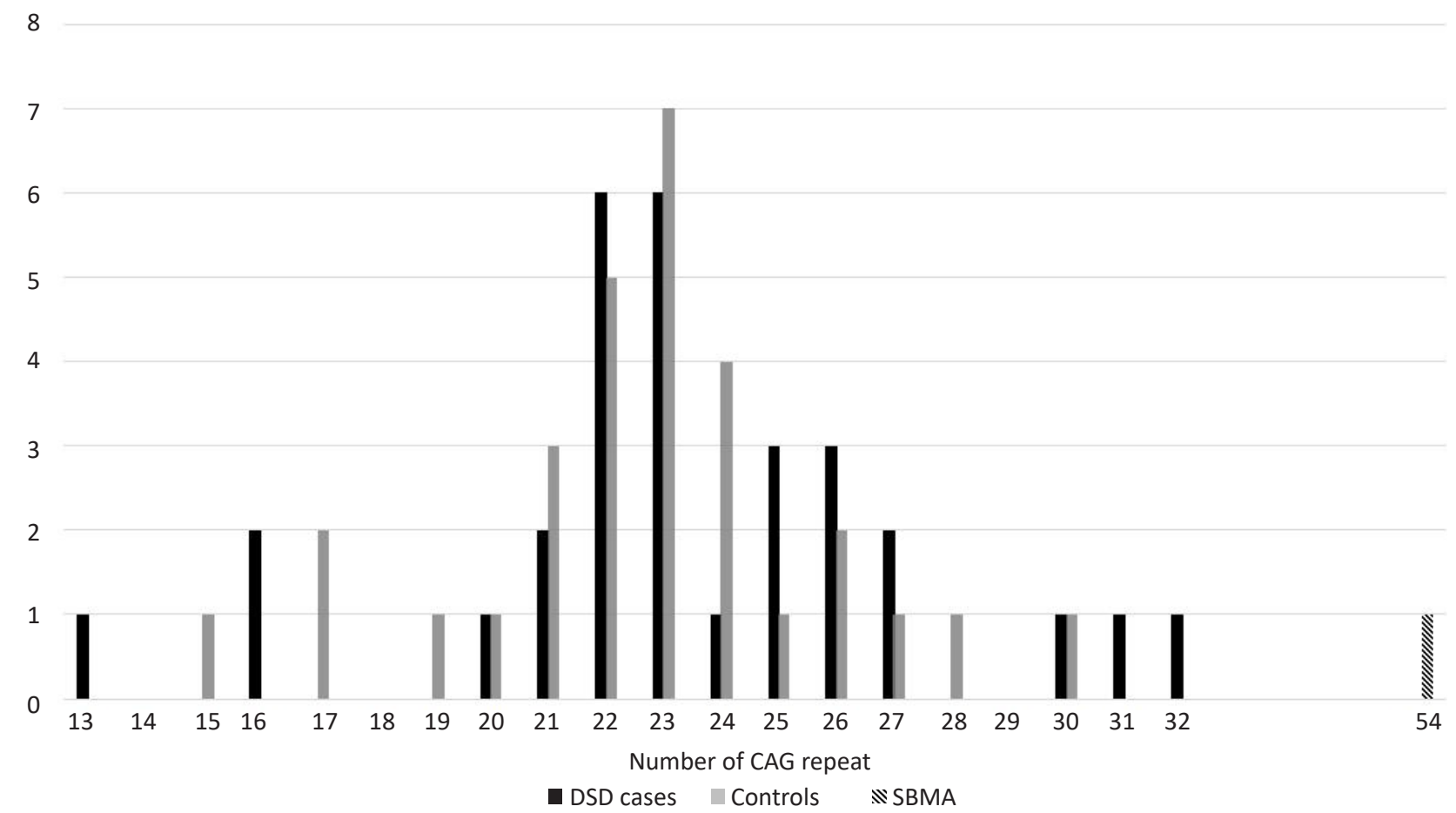

Figure 1. Distribution of the CAG repeat lengths at exon 1 of the $A R$ gene in the DSD cases, SBMA case, and controls. $A R=a n d r o g e n$ receptor; DSD=disorder of sex development; SBMA=spinal and bulbar muscular atrophy

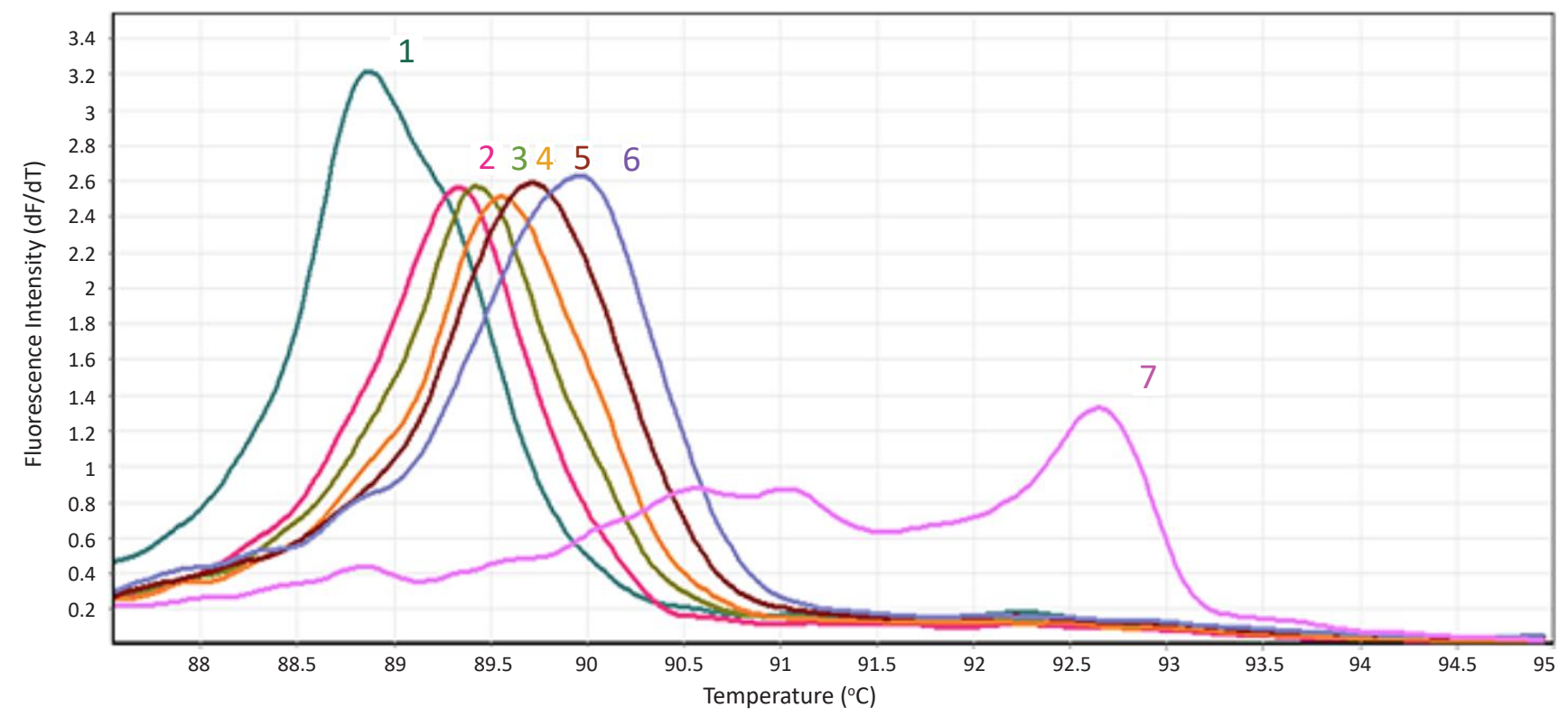

Figure 2. HRM analysis of exon 1 of the AR gene revealed melting curves of DNA sequences from seven samples. Different colors represent different sequences from each sample. The highest melting temperature $\left(92.65^{\circ} \mathrm{C}\right)$ is shown in the SBMA sample with 54 CAG repeats (no 7). The details of the melting curve in the graph are as follows: the DSD sample with 13 CAG repeats (no 1) and the control sample with 17 (no 2), 19 (no 3), 21 (no 4), 24 (no 5), and 27 (no 6) CAG repeats. HRM=high resolution melting; AR=androgen receptor; $\mathrm{SBMA}=$ spinal and bulbar muscular atrophy; $\mathrm{DSD}=$ disorder of sex development 


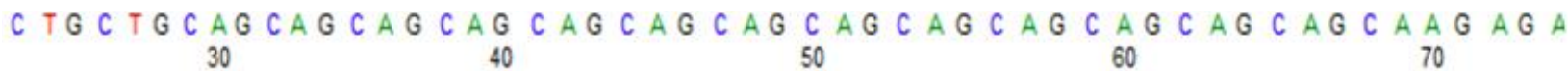

a

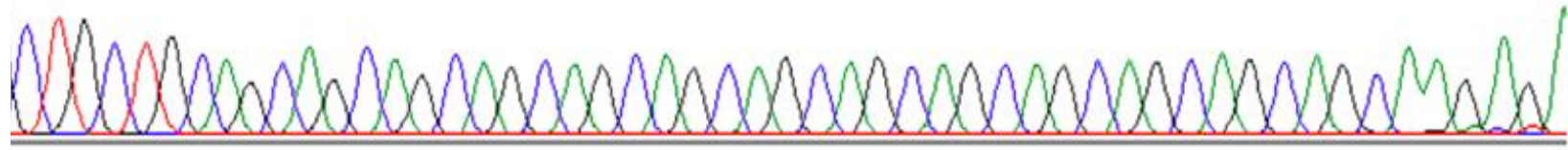

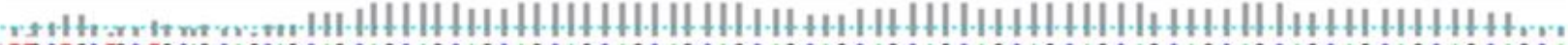
TIOCT GC TOC TOCUG CAGCAG CAG CAGC AG CAGCAG CAGCAGC AG CAGC AG CAGC AG CAGC CAGCAG CAGC AG CAGCAG CAGC CAG CAGCAG CAGC

b

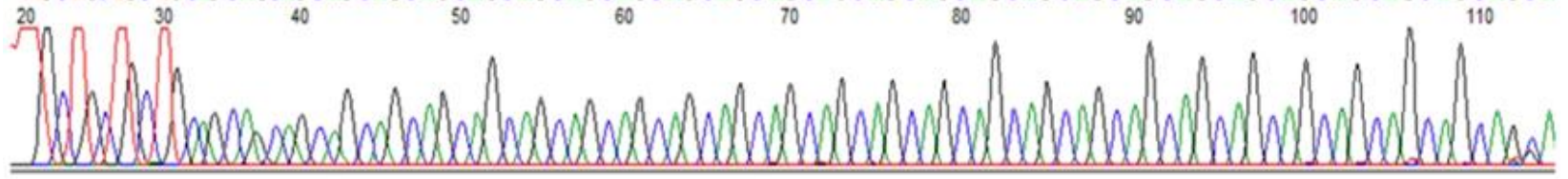

CAGCAGCAGCGCAGCAGCAGCAGCAGCAGCACAGCAGCAGCAGCAGCAGCAGCAGCAGCAGCAGCAGAGCAGCAGAGCAGCAG

C

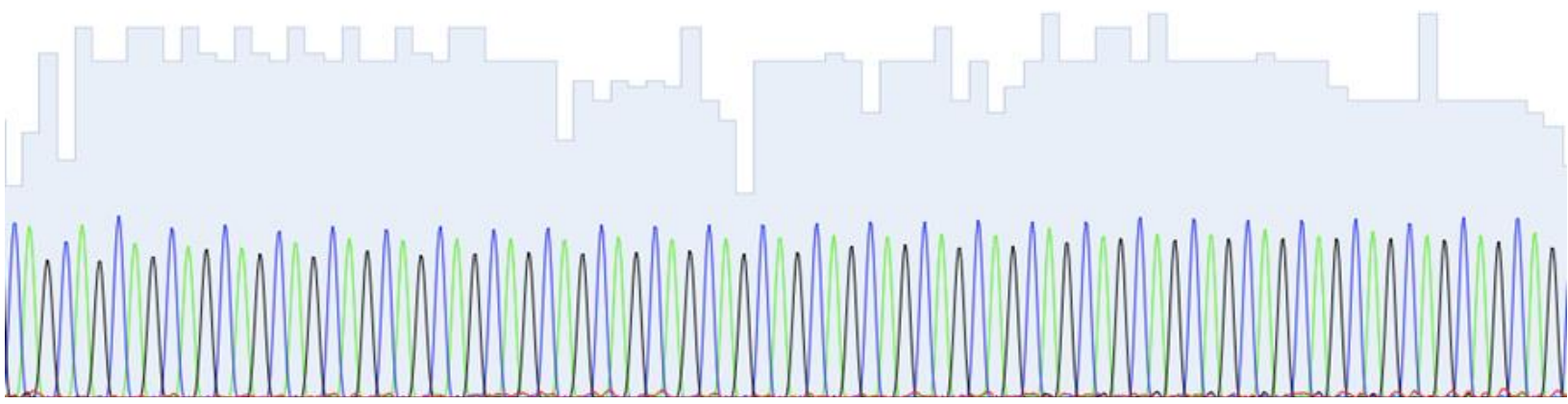

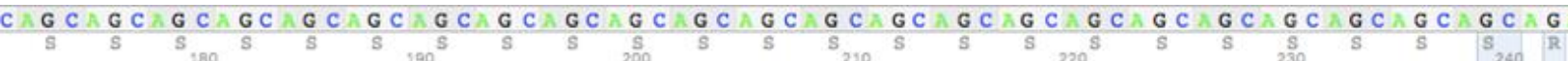

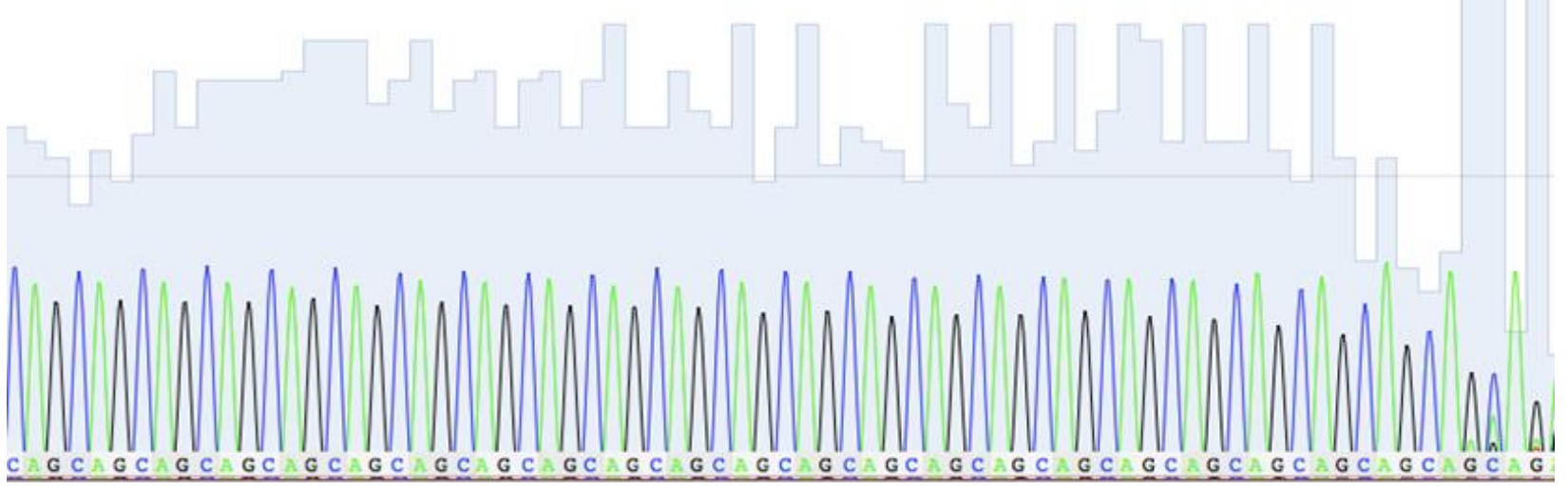

Figure 3. Sequence analysis of samples (forward direction). CAG repeats were identified from exon 1 of the AR gene. (a) The lowest length (13 repeats) was found in the DSD sample and; (b) The highest length (27 repeats) was found in the control sample; (c) The expanded 54 CAG repeat was found in the SBMA sample. AR=androgen receptor; $D S D=$ disorder of sex development; SBMA=spinal and bulbar muscular atrophy

groups, respectively (Figure 1). A Mann-Whitney U-test showed no significant differences $(p=0.381)$ between the control (Median [SD] = 23 [2.62]) and DSD groups (Median [SD] = 23 [2.7]). MCA in DSD and control groups revealed that the minimum $\mathrm{Tm}$ value was $88.87^{\circ} \mathrm{C}$ (13 CAG repeats) and the maximum value was $89.95^{\circ} \mathrm{C}$ ( $27 \mathrm{CAG}$ repeats). The SBMA case showed 54 CAG repeats with $\mathrm{Tm}$ at $92.65^{\circ} \mathrm{C}$ (Figure $2)$. Sanger sequencing was performed to confirm the CAG repeat length. Figure 3 shows the highest 
Figure 4. Spearman's correlation analysis of CAG repeat length ( $n=61$ samples) and melting point. The line shows linear regression $\left(r^{2}=0.678\right)$ with a moderate, positive correlation between CAG repeat length and melting point, which was statistically significant $\left(r_{s}=0.512, p<0.01\right)$

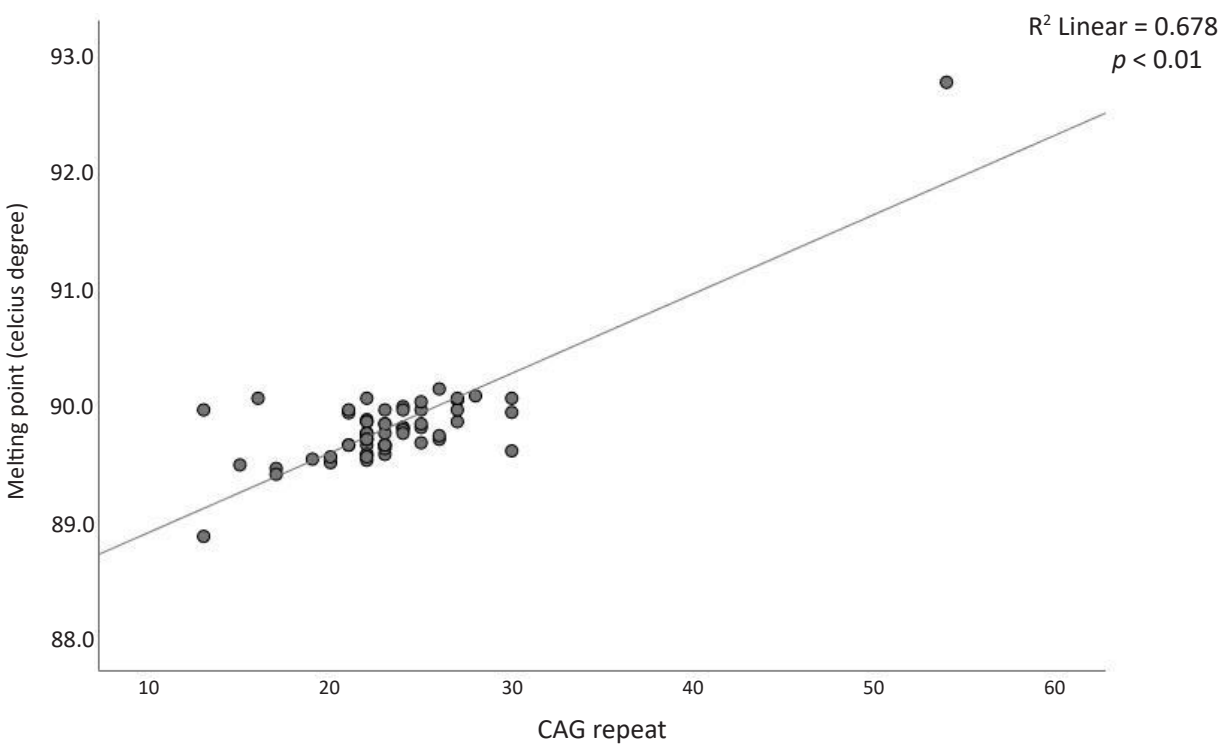

and lowest range of CAG repeats, along with the expanded CAG repeat. Furthermore, Spearman's rank-order correlation revealed a moderate, positive correlation between the CAG repeat length and Tm with a correlation coefficient of $0.512(p<0.01$ with $r^{2}=67.8 \%$; Figure 4).

\section{DISCUSSION}

AR gene mutations can cause various phenotypic abnormalities, and they are the leading cause of DSD and are associated with androgen insensitivity syndrome, male infertility, prostate cancer, and SBMA. Patients born with 46, XY DSD have a higher risk of infertility because of androgen receptor disruption. ${ }^{13}$ Numerous studies have attempted to establish the association between CAG repeat length variation and male infertility. ${ }^{5}$ Adamovic and Nordenskjöld7 have reported that CAG repeat polymorphism in the $A R$ gene is associated with the risk of hypospadias in the Caucasian population. Therefore, $A R$ gene screening using a simple and rapid technique is required to detect whether the $A R$ gene polymorphism is associated with male reproductive disorders.

In this study, the CAG repeat lengths were similar and within the normal range in the DSD and control groups. These results are in accordance with a previous report by Muroya et $\mathrm{al}^{14}$ because the CAG repeat length of the $A R$ gene was not a major factor in the development of hypospadias. CAG repeat lengths appear to negatively affect the atypical phenotype in the DSD group. However, the CAG repeat length within the normal range does not eliminate the possibility of infertility and histological abnormality of the testis in our DSD cases. Fietz et $\mathrm{al}^{15}$ demonstrated no correlation between CAG repeat length and the histology of the testis.

Diagnosis of DSD in Indonesia involves a multistep approach including clinical examination, chromosomal analysis, internal genitalia ultrasound, and mutation analysis. In Indonesia, a high prevalence of 46, XY DSD (65.9\%) has been reported. ${ }^{16}$ However, there are obstacles to accurate DSD diagnoses in Indonesia because of a lack of awareness regarding genetic diseases, advanced laboratory facilities, and health insurance coverage.

Sanger sequencing has been considered to be the gold standard for CAG repeat length analysis; however, it is more a laborious, time-consuming, and expensive procedure. While HRM analysis is a costeffective, less laborious, and rapid technique and requires only one-step real-time $P C R$ compared with Sanger sequencing ${ }^{17,18}$ and restriction fragment length polymorphism-Southern blot analysis. ${ }^{19}$ In developing countries with limited molecular diagnostic facilities, HRM analysis can be more useful, particularly for research and population screening.

HRM analysis is a cost-effective, less laborious, and rapid technique and requires only one-step realtime PCR compared with Sanger sequencing ${ }^{17,18}$ and restriction fragment length polymorphism-Southern blot analysis. ${ }^{19}$ In developing countries with limited 
molecular diagnostic facilities, HRM analysis can be more useful, particularly for research and population screening.

In this study, the patient with SBMA showed CAG repeat expansion in exon 1, and the amplicon contained more CAG repeats that shifted the melting curve to the right. The polyglutamine sequence of $A R$ containing GC-rich codons increases Tm when CAG repeat expansion occurs. ${ }^{9}$ An increase in Tm was moderately associated with an increase in CAG repeat length, indicating that a higher Tm during HRM analysis corresponds to CAG repeat expansion $(p<0.01)$. The degree of correlation may be influenced by the normal range and small interval of CAG repeats among all samples of the DSD and control groups, excluding the SBMA sample. This finding can be utilized for rapid screening of CAG repeat expansion in SBMA and other TRE diseases. Nevertheless, the identification of CAG repeat for androgen insensitivity syndrome (partial or complete type) must not be suggested because of its various mutations in almost all eight exons. ${ }^{20}$

The expansion of the polyglutamine sequence has been reported to be associated with neurodegenerative genetic diseases such as SBMA, Huntington's disease, and spinocerebellar ataxia. The expansion alters the $\mathrm{N}$-terminal region that causes $A R$ dysfunction resulting in partial loss of $A R$ function. ${ }^{21}$ The length of CAG repeat in the range of 38-62 can cause SBMA and develop signs of androgen insensitivity such as gynecomastia and infertility, in addition to neurodegenerative symptoms..$^{22}$ In this study, CAG repeat expansion were not detected, and no correlation was observed between the atypical phenotype in 46, XY DSD cases and normal repeat length of CAG in the AR gene, probably because of small sample size, various types of hypospadias or genital anomaly, ethnic background, and several other genes that caused DSD with a similar phenotype.

A similar technique was performed in CGG repeats of FMR1 gene for screening Fragile $X$ syndrome with a considerably high sensitivity and specificity..$^{10}$ This study is the first study in Indonesia using HRM analysis for screening CAG repeats in the AR gene. In addition, screening using triplet repeat primed $P C R$ and HRM for other TRE diseases can be considered. For neurodegenerative diseases with similar clinical symptoms, HRM analysis can be used for determining molecular pathology and rapid diagnosis. However, this technique can only detect expanded alleles and cannot identify the number of CAG repeats.

\section{Limitations of the study}

The limitations of the study are as follows. First, HRM analysis could only identify CAG repeat expansion in both alleles of the AR gene; however, it could not identify the number of CAG repeats. Second, although HRM analysis is rapid and costeffective, Sanger sequencing may be required to confirm the number of CAG repeats required. Third, the sample size used in this study was small for genetic studies. For future studies, a larger sample size of patients with DSD and SBMA must be considered to elucidate the prevalence of CAG repeats expansion in exon 1 of the $A R$ gene.

\section{Conclusions}

In conclusion, PCR-HRM is a rapid and cost-effective technique for screening CAG repeat expansion in the $A R$ gene and can be used as a diagnostic tool for detecting other TRE diseases. This study revealed that CAG repeat expansion in the AR gene in DSD cases is scarce in the Indonesian population; nevertheless, the CAG repeat expansion could not be identified in one SBMA case. This is a rapid and inexpensive technique for AR gene screening that may be applicable to other TRE diseases.

\section{Conflict of Interest} declare.

All authors certify that they have no conflict of interest to

\section{Acknowledgment}

We thank Dr. Ferdy K Cayami, Dr. Gema Citra, and Dr. Gerard Pals for their help in sequence analysis.

\section{Funding Sources}

This study was supported by Competitive Research Grant by Diponegoro University-Riset Unggulan UNDIP/DIPA number: 023.04.2.189815/2015 and DIPA number: 042.01.2.400898/2016.

\section{REFERENCES}

1. Sanders DW, Brangwynne CP. RNA repeats put a freeze on cells. Nature. 2017;546(7657):215-6.

2. La Spada AR, Taylor JP. Repeat expansion disease: progress and puzzles in disease pathogenesis. Nat Rev Genet. 2010;11(4):247-58.

3. Ryan CP, Crespi BJ. Androgen receptor polyglutamine repeat number: Models of selection and disease susceptibility. Evol Appl. 2013;6(2):180-96.

4. Pan B, Li R, Chen Y, Tang Q, Wu W, Chen L, et al. Genetic association between androgen receptor gene cag repeat length polymorphism and male infertility: a meta-analysis. Medicine (Baltimore). 2016;95(10):e2878. 
5. Tirabassi G, Cignarelli A, Perrini S, Delli Muti N, Furlani $G$, Gallo $M$, et al. Influence of CAG repeat polymorphism on the targets of testosterone action. Int J Endocrinol. 2015;2015:298107.

6. La Spada AR, Wilson EM, Lubahn DB, Harding AE, Fischbeck KH. Androgen receptor gene mutations in X-linked spinal and bulbar muscular athrophy. Nature. 1991;352(6330):77-9.

7. Adamovic T, Nordenskjöld A. The CAG repeat polymorphism in the androgen receptor gene modifies the risk for hypospadias in Caucasians. BMC Med Genet. 2012;13:109.

8. Wittwer CT, Reed GH, Gundry CN, Vandersteen JG, Pryor RJ. High-resolution genotyping by amplicon melting analysis using LCGreen. Clin Chem. 2003;49(6):853-60.

9. Sharma N, Nautiyal SC, Kumari S, Kumari K, Singh V, Kumar K, et al. High resolution melt curve analysis- an innovative approach for molecular diagnosis. Webmed Cent. 2013;4(3):WMC003998.

10. Lim GX, Yeo M, Koh YY, Winarni TI, Rajan-Babu IS, Chong SS, et al. Validation of a commercially available test that enables the quantification of the numbers of CGG trinucleotide repeat expansion in FMR1 gene. PLoS One. 2017;12(3):e0173279.

11. Miller SA, Dykes DD, Polesky HF. A simple salting out procedure for extracting DNA from human nucleated cells. Nucleic Acids Res. 1988;16(3):1215.

12. Greenland KJ, Beilin J, Castro J, Varghese PN, Zajac JD. Polymorphic CAG repeat length in the androgen receptor gene and association with neurodegeneration in a heterozygous female carrier of Kennedy's disease. J Neurol. 2004;251(1):35-41.

13. Tahmasbpour E, Balasubramanian D, Agarwal A. A multi-faceted approach to understanding male infertility: gene mutations, molecular defects and assisted reproductive techniques (ART). J Assist Reprod Genet. 2014;31(9):1115-37.

14. Muroya K, Sasagawa I, Suzuki Y, Nakada T, Ishii T, Ogata T. Hypospadias and the androgen receptor gene: mutation screening and CAG repeat length analysis. Mol Hum Reprod. 2001;7(5):409-13.

15. Fietz D, Geyer J, Kliesch S, Gromoll J, Bergmann M. Evaluation of CAG repeat length of androgen receptor expressing cells in human testes showing different pictures of spermatogenic impairment. Histochem Cell Biol. 2011;136(6):689-97.

16. Juniarto $A Z$, van der Zwan YG, Santosa A, Hersmus R, de Jong $\mathrm{FH}$, Olmer R, et al. Application of the new classification on patients with a disorder of sex development in Indonesia. Int J Endocrinol. 2012;2012:237084.

17. Jancik S, Drabek J, Berkovcova J, Xu YZ, Stankova M, Klein J, et al. A comparison of direct sequencing, pyrosequencing, high resolution melting analysis, TheraScreen DxS, and the K-ras StripAssay for detecting KRAS mutations in non small cell lung carcinomas. J Exp Clin Cancer Res. 2012;31(1):79.

18. Marino M, Monzani ML, Brigante G, Cioni K, Madeo B, Santi $D$, et al. High-resolution melting is a sensitive, cost-effective, time-saving technique for BRAF V600E detection in thyroid fnab washing liquid: a prospective cohort study. Eur Thyroid J. 2015;4(2):73-81.

19. Ghasemi Z, Hashemi M, Ejabati M, Ebrahimi SM, Manjili HK, Sharafi $A$, et al. Development of a high-resolution melting analysis method for $\mathrm{CYP}_{2} \mathrm{C}_{19} *_{17}$ genotyping in healthy volunteers. Avicenna J Med Biotechnol. 2016;8(4):193-9.

20. Gottlieb B, Beitel LK, Nadarajah A, Paliouras M, Trifiro M. The androgen receptor gene mutations database: 2012 update. Hum Mutat. 2012;33(5):887-94.

21. Davey RA, Grossmann M. Androgen receptor structure, function and biology: from bench to bedside. Clin Biochem Rev. 2016;37(1):3-15.

22. Grunseich C, Rinaldi C, Fischbeck KH. Spinal and bulbar muscular atrophy: pathogenesis and clinical management. Oral Dis. 2014;20(1):6-9. 